\title{
How to measure uncertainties in environmental risk assessment
}

\author{
R.M. Darbra, E. Eljarrat, D. Barceló
}

Environmental risk assessment is an essential element in any decision-making process in order to minimize the effects of human activities on the environment. Unfortunately, often environmental data tends to be vague and imprecise, so uncertainty is associated with any study related with these kind of data.

Essentially, uncertainty in risk assessment may have two origins - randomness and incompleteness. There are two main ways to deal with these uncertainties - probability theory and fuzzy logic.

Probability theory is based on a stochastic approach, using probability functions to describe random variability in environmental parameters.

Fuzzy logic uses membership functions and linguistic parameters to express vagueness in environmental issues.

We discuss the best way to deal with uncertainties in the environmental field and give examples of probabilistic and fuzzy-logic approaches applied to environmental risk assessment.

(c) 2008 Elsevier Ltd. All rights reserved.

Keywords: Environmental risk assessment; Fuzzy logic; Monte Carlo; Probability theory; Uncertainty

R.M. Darbra, E. Eljarrat, D. Barceló*

Department of Environmental Chemistry, IIQAB, CSIC, Jordi Girona 18-26, 08034 Barcelona, Spain

${ }^{*}$ Corresponding author Tel.: +34 93400 6100; Fax: +34932045904 E-mail: dbcqam@cid.csic.es

\section{Introduction}

The growing concern about the environment and the potential risks associated with many human activities and new technologies have created increasing interest in environmental risk assessment, which is a critical, essential part of any decisionmaking process. It offers sound bases for assessing and ranking potential pollution of the environment, so the evaluation of environmental risk due to anthropic activities is an important step in mitigating their impact on natural resources and in recreating the co-evolutionary process between human and natural components of the environment [1].

Decision makers of ecological policy and management require sound scientific information on the environmental risk associated with many different activities in order to arrive at and to justify their decisions [2], so there is a need to evaluate all potential risks that can cause environmental damage. The results of this environmental risk assessment should be communicated to the decision makers and regulators in a common, sound language to allow them to take the most appropriate decisions.

Estimating risk involves identifying the events that present hazards and produce risk, communicating the magnitude of the consequences associated with these events, and estimating the likelihood of a given risk [3]. However, this process is not so straightforward as one might imagine. For a complete environmental risk assessment, a great amount of data is required. In some cases, extensive statistical data may be available and can contribute to an understanding of the frequency and the severity of the hazard. However, it is very common that environmental data is qualitative, vague or imprecise, especially in the case of newly emerging contaminants.

As stated by Uricchio et al. [4], incomplete information is notoriously common in environmental issues. This imprecision of the environmental data, together with the randomness of the events and the role that human judgment plays in determining the risk and communicating its significance, means that there is uncertainty associated with risk assessment.

The proper management of this uncertainty has become a major concern in studies of environmental risk assessment [5]. In response, research is under way to explore techniques that can incorporate uncertainty and imprecision into the assessment process [3].

It has been found from the literature review that stochastic and fuzzy-set techniques have been commonly used to accommodate uncertainties associated with risk-modeling inputs and outputs. Stochastic techniques may be known as a 
"scientific reasoning model", based on probability theory, and the fuzzy-set techniques may be known as a "human reasoning model", based on linguistic parameters and qualitative assessment.

In this article, we discuss the suitability of both methodologies to deal with uncertainty, and provide applications of these approaches to environmental risk assessment.

\section{Risk assessment and risk management}

According to Varnes [6], risk is generally defined as the combination of hazard and vulnerability; hazard represents the probability that a potentially detrimental event of given characteristics occurs in a given area, for a time period; vulnerability is the degree of intrinsic weakness of the system.

Risk can be measured by pairing the probability of occurrence of an event, and the outcomes or consequences associated with that occurrence. This pairing is not a mathematical operation, a scalar or vector quantity, but a matching of the probability of the event occurring with the expected consequence [7].

Risk assessment can be defined as the process of estimating the possibility that a particular event may occur under a given set of circumstances [2]. But risk management is the process whereby decisions are made about whether an assessed risk needs to be managed, and the means for accomplishing that management, for the protection of public health and environmental resources [8].

Risk assessment could be considered as the most important step in the risk-management process (i.e. decision-making process). It provides a scientific, sound basis for making decisions. Managing risks should involve making decisions based on the information collected in risk assessment. However, it is important to remember that the final decision of how to manage risk is generally human in nature. This means that, apart from the results gathered in the risk assessment, social and cultural values, economic realities and political factors are borne in mind. According to Barnthouse [9], the role of science in risk assessment is to ensure that the actions implemented by environmental managers achieve the goal and the objectives defined by society.

Fig. 1 presents the steps in environmental risk management. The first step is to establish the context in which environmental risk is assessed (e.g., river water or groundwater). After this, it is necessary to identify the potential sources of environmental risk (e.g., releases of chemical products into a river). At the third step, predictions of the frequency and the consequences of the event are required. There are different techniques to assess these parameters [10,11] (e.g., event trees, historical analysis and HAZOP). From these results, a risk categorization and a final risk assessment of the situation can be obtained. Steps 1-4 provide the basis for the rest of the process of risk management, known as risk assessment. Once the risk assessment has been conducted, an environmental risk plan has to be developed in order to establish targets, means and timeframe to reduce the risk that has been identified and assessed. After this, the plan must be implemented and finally reviewed to check that it works properly.

Despite the unquestionable appropriateness of risk assessment as a tool to help in the decision-making process, it can be the part of the whole risk-management process that is most difficult and prone to error, mainly because uncertainty in the measurements of hazard and vulnerability is often large. Insight about risks is limited by the randomness inherent in nature and the lack of sufficient information about the chances of a risk occurring and the potential consequences of such an occurrence. As a result, uncertainty is inherent in risk assessment $[12,13]$.

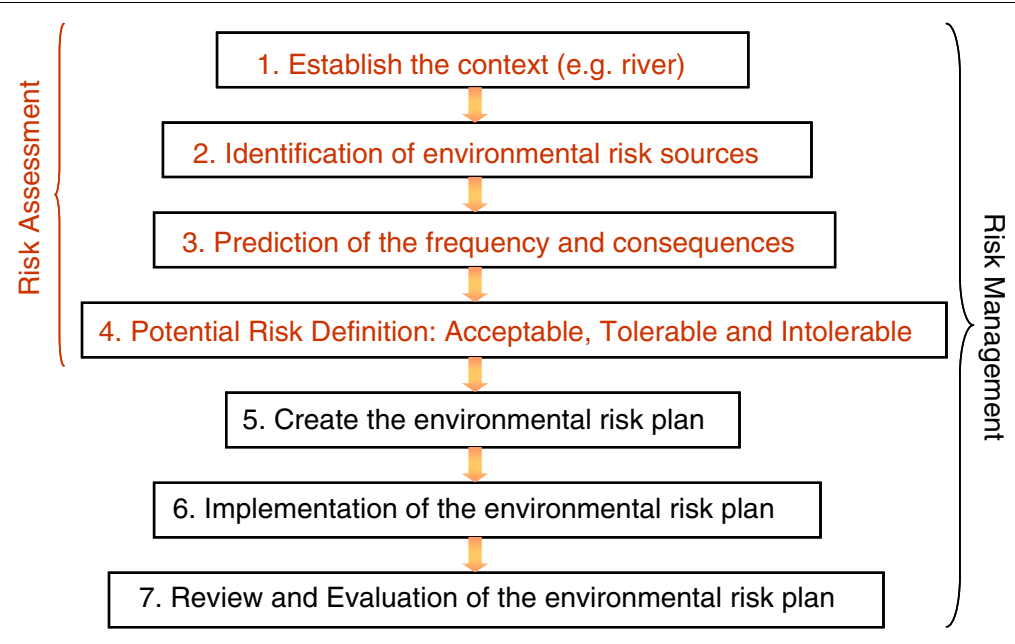

Figure 1. Steps in environmental risk management. 
In spite of these limitations, there is large consensus in the scientific community about the usefulness of risk assessment as an appropriate tool for attaining a reasonable compromise between a sound scientific approach and the need for simple, transparent and pragmatic decision-making instruments [2]. However, in order to make the best decision, the existence of uncertainty in risk assessment needs to be borne in mind.

\section{Dealing with the uncertainty}

Uncertainty can be described as a lack of knowledge regarding the true value of a parameter [14]. This concept often appears in modeling environmental systems, particularly in uncertainty concerning the data and the relations between the system components [15].

As risk assessments have become important aids in the decision-making process for the management of sources of contamination, uncertainty with respect to the values of model parameters is of primary importance [16].

Essentially, there are two sources of uncertainty affecting parameters in risk assessments:

(1) randomness (due to variability of phenomena, or because all factors affecting the system being studied cannot be modeled); and,

(2) incompleteness (when there is simply a lack of information regarding parameter values).

The ideal way to address uncertainty due to randomness is to collect data and perform a statistical analysis. When information is incomplete or statistical data are not available, human experts can supply information on parameter values [16].

It is therefore possible to classify the uncertainties associated with risk in two broad categories $[17,7]$ :

(1) stochastic (due to the randomness); and,

(2) cognitive (due to the vagueness of expert's judgments).

To accommodate these kinds of uncertainty, there are two main techniques:

(1) probability theory (for stochastic uncertainties); and,

(2) possibilistic theory (i.e. fuzzy logic) for cognitive uncertainties.

In the probabilistic approach, probability distributions are used to describe random variability in parameters. However, in the possibilistic or fuzzy-set approach, membership functions are used to characterize vagueness in human thought. The rationales behind these two approaches for dealing with uncertainty are different [18]. The probabilistic approach is widely used when sufficient information is available for estimating the probability distributions of uncertain parameters, while the fuzzy-set method is well suited to dealing with uncertainties when little information is known (i.e. imprecise knowledge associated with human-language descriptions) [19].

\subsection{Probability theory}

Traditionally, probability theory was one of the methodologies used most in risk assessment. Probabilistic risk assessment (PRA) is the general term for risk assessment that uses theory and models to represent the likelihood of different risk levels in a population (i.e. variability) or to characterize the uncertainty in risk estimates [20-23]. Assuming all uncertainty is due to randomness, PRA uses probability distributions for one or more variables in a risk equation in order to quantify variability and/or uncertainty in the outcome. The output of a PRA is a probability distribution of risk that reflects the combination of the input probability distributions.

Among various probabilistic techniques to quantify uncertainties, the most widely used approach has been Monte-Carlo analysis (MCA) [24]. MCA is a probabilistic method that uses computer simulation to combine multiple probability distributions in a risk equation. It uses repeated executions of a numerical model [25].

MCA, which applies probability theory to address model-parameter uncertainty, relies on statistical representation of available information. It assumes that the model parameters are random variables that can be represented by probability-density functions (PDFs). If $X$ is considered as a random variable, and the probabilities $(P)$ that $X$ should be less than or equal to values $x$ of $X$ are known, PDF $F(x)$ can be defined as [16,26]:

$F(x)=P(X \leqslant x)$

If variable $X$ is continuous (i.e. it can take any value within a defined range), PDF $f(x)$ can be defined as:

$f(x)=d F(x) / d x$

When detailed information about the situation and environmental data are available and statistics can be performed, then probability theory is an excellent tool to assess risk and to quantify uncertainty. However, a serious shortcoming of this method is that it is not capable of coming to grips with the pervasive fuzziness of information in the knowledge base, and, as a result, is mostly ad hoc in nature [27].

\subsection{Fuzzy logic}

Fuzzy-logic systems provide an alternative to classical logic and have their origins in ancient Greek philosophy [28]. But, it was not until the mid-1960s that the notion of a multi-valued logic took hold, when Zadeh [29] published his seminal work "Fuzzy Sets" in order to provide a model for inexact concepts and subjective judgments similar to those encountered in risk assessment.

Fuzzy logic represents a significant change in both the approach to and the outcome of environmental 
evaluations. The key advantage of fuzzy-logic methods is how they reflect the human mind in its remarkable ability to store and to process information that is consistently imprecise, uncertain, and resistant to classification [30].

Fuzzy logic has the power to handle the concept of "partial truth" to quantify uncertainties associated with linguistic variables [31]. It can define a "degree of membership" of an element in a set by means of a membership function. For classical or "crisp" sets, the membership function takes one of only two values: 0 (non-membership) and 1 (membership). In fuzzy-logic sets, the membership function can take any value in the interval $[0,1]$. The value 0 represents complete nonmembership, the value 1 represents complete membership, and values in between are used to represent partial membership [32,33].

For the types of complex, imprecise problems that arise in environmental policy, the ability to model complex behaviors as a collection of simple "if-then" rules makes fuzzy logic a useful tool in risk assessment [30]. It is also useful when making decisions, since communication of risk-assessment results in linguistic terms leads to an approach understandable to the decision makers and the public.

Fuzzy-logic set theory provides a way to use imprecise, uncertain information generated by the system and human judgments in a precise way [15]. When the environmental data available does not provide proper statistical treatment, fuzzy arithmetic can solve this problem, since it works well for addressing poorly characterized parameters and linguistic variables. Fuzzy logic also can merge different kinds of parameters (e.g., environmental and health, and quantitative and qualitative). However, fuzzy logic has at least has two limitations:

- strong reliance on subjective inputs; and,

- it can fail to capture the ranges of values in complex data sets and the correlations among the parameters [34].

\subsection{Fuzzy logic versus probability}

Traditionally, researchers used probability theory, especially MCA, to evaluate uncertainty and variability in risk assessment $[14,35,36]$. It was assumed that probability theory provided necessary and sufficient tools for dealing with uncertainty and variability. Environmental information was interpreted in a probabilistic sense and probability theory was used to integrate the data into mathematical models.

Probability theory is a very strong and well-established mathematical tool to treat variability. It has certain input requirements and, whenever these requirements are met, probability theory will provide powerful results. When uncertainty is considered to be exclusively a result of randomness, probability theory and statistics are adequate to deal with such uncertainty. However, it is clear that not all uncertainties in data or model parameters are random, so they cannot be treated by statistical approaches alone [24].

According to Lein [3], when attempting to model the behavior of environmental processes, analysis often suffers from a lack of data or imperfect knowledge about processes that frustrates rigorous probabilistic study. As a result, the direct application of environmental risk analysis via Monte-Carlo simulation methods may lead to two potential shortcomings:

(1) first, risk analysis using Monte-Carlo outputs requires that distributions of input parameters should be precisely specified; and,

(2) second, researchers mostly assume that input parameters are independent of one another even though they are obviously not.

Although methods to simulate correlations among parameters exist, they are not detailed enough for further risk quantification, especially when the dependencies are not well known. As a result, uncertainties still exist in the Monte-Carlo simulation outputs [19].

Moreover, in applications, risk analysis often suffers from lack of data or presence of sparse, imperfect, and heuristic information about the processes and the process parameters [3,37], so, in such cases, it is questionable if realistic probability distributions can be assigned to the parameters of the environmental risk model. When sufficient data are not available to assign PDFs to the parameters of the risk equation, it may be more reasonable to characterize these parameters by other means, such as fuzzy-logic numbers [24].

In contrast to PDFs, fuzzy-logic membership functions express the possibility of an outcome rather than the likelihood of an outcome. In a probabilistic approach, we model uncertainty by expressing our belief that an event either occurs or does not. But with fuzzy logic, we model uncertainty as the degree of membership in the set that defines an outcome [30]. The main breakthrough of fuzzy-logic interference compared with traditional mathematical models lies in the fact that relationship between inputs and outputs is not determined by complex equations, but by a set of logical rules, reflecting an expert's knowledge [38].

After such a discussion about the suitability of the probabilistic and possibilistic approach, one could think about the diversity of environmental parameters (e.g., units and typology) involved in any risk assessment. Then, one might consider it more realistic to assign probability distributions to certain parameters, while others would be represented by fuzzy-logic numbers. In this way, the manner in which parameter uncertainty is described in the model can be more consistent with the basic nature of the information at hand [26].

This new approach has lead to use fuzzy-logic set theory in combination with probabilistic methods to generate hybrid approaches for risk-assessment studies [16,24,26,39]. Some authors, such as Blair et al. [7], 
believe that uncertainty manipulation through individual approaches may not be feasible in real-world situations when different information qualities exist for various parameters.

In practice, certain model parameters may be reasonably represented by probability distributions, because there are sufficient data available to substantiate such distributions by statistical analysis, while others are better represented by fuzzy-logic numbers (due to data scarcity).

The main advantage of the hybrid approach is that it takes advantage of the "rich" information provided by probability distributions. While retaining the conservative character of fuzzy-logic calculus, it is believed to hold value in terms of a "reasonable" application of the precautionary principle. In addition, it clearly distinguishes between the case where the precise value of a parameter is unknown because of its statistical variability, and the case where it is unknown due to a simple lack of observed data. The potential apparent drawbacks are that it may deliver poorly informative results in some situations [16] and there may also be the difficulty of joining both methodologies in one system that can identify without error the different types of variables.

\section{Environmental risk applications}

Although risk assessment has been a very common subject of discussion for many years, applications to the environmental field are quite recent. Traditionally, the probabilistic approach was the most used in risk assessment and considered appropriate to deal with the uncertainties of risk. But, when some experts realized that probabilistic models could fail to provide satisfactory descriptions of phenomena, applications of fuzzy logic started to be more common [3]. Recently, some researchers have explored the possibility of carrying out environmental risk assessment by combining two different modes of representation of uncertainty (i.e. probabilistic and possibilistic theories) in a single computational procedure, known as the "hybrid approach". We give examples of these three approaches to the field of environmental risk assessment (see also Table 1).

\subsection{Probabilistic applications}

For groundwater risk assessment, a methodology to predict health risks to individuals from contaminated groundwater using probabilistic techniques was developed by Maxwell et al. in 1999 [20]. This approach incorporated the elements of uncertainty and variability in geological heterogeneity, physiological exposure parameters, and cancer potency. A two-dimensional distribution (or surface) of human-health risk was generated as a result of the simulations.

In 2002, Passarella et al. [40] developed an approach to assess the risk of groundwater-quality degradation with regard to fixed standards, based on a probabilistic methodology, Disjunctive Kriging (DK), which allowed one to evaluate the conditional probability $(\mathrm{CP})$ of overriding a given threshold of concentration of a pollutant at a given time, and at a generic point in a groundwater system. The result of such investigation over the area being considered was plotted in the form of maps of spatial risk.

For waste-risk assessment, we present three applications. First, Batchelor et al. [41] developed a procedure to apply a stochastic risk-assessment model to sites contaminated by hazardous waste. Such a model was developed for a site contaminated with polychlorinated biphenyls (PCBs) by representing the parameters used in the risk assessment as PDFs rather than single values.

Second, in 1999, Draper et al. [42] applied probability theory in risk assessments related to the underground disposal of nuclear waste. Six variables were required for such risk assessment (i.e. past data, future observables, scenario, and structural, parametric and predictive uncertainties). The risk model was applied to nuclear waste disposal using a computer simulation environment - GTMCHEM - which "deterministically" modeled the one-dimensional migration of radionuclides through the geosphere up to the biosphere.

Third, the risk generated by a municipal waste incinerator was assessed by Schumacher et al. [14] using Monte-Carlo simulation techniques. The incremental lifetime risks for the residents living in the surroundings of a municipal solid-waste incinerator (MSWI) were assessed. Using probabilistic techniques, two different pathways of exposure to polychlorinated dibenzo-pdioxins and dibenzofurans (PCDD/Fs) were assessed and compared - ingestion through the diet and exposure from the emissions of the MSWI.

In the case of polluted sites, Labieniec et al. [43] used PDFs to address uncertainty in estimating the risk of human exposure due to the presence of contaminated land. They evaluated the uncertainty in predicted carcinogenic risk resulting from uncertainty in site properties and fate and transport predictions for a simple site with contaminated soil.

Ma [22] presented a methodology for incorporating uncertainty and variability into a multi-medium, multipathway, multi-contaminant risk assessment, and for placing this assessment into an optimization framework to identify optimal management strategies. The framework was applied to a case study of a sludge-management system proposed for North Carolina and the impact of stochasticity on selection of an optimal strategy was considered.

\subsection{Fuzzy applications}

Again for groundwater-risk assessment, we highlight two works. First, Dahab et al. [44] introduced a rule-based fuzzy-set approach to risk analysis of 


\begin{tabular}{|c|c|c|c|}
\hline Environmental field & Method used & Application & Ref. \\
\hline Groundwater & $\begin{array}{l}\text { Probabilistic techniques creating two-dimensional } \\
\text { distributions }\end{array}$ & $\begin{array}{l}\text { Assessment of risk to health of individuals from } \\
\text { contaminated groundwater }\end{array}$ & {$[21]$} \\
\hline Groundwater & $\begin{array}{l}\text { Probabilistic methodology based on Disjunctive } \\
\text { Kriging }\end{array}$ & $\begin{array}{l}\text { Maps of spatial risk concerning groundwater- } \\
\text { quality degradation }\end{array}$ & {$[40]$} \\
\hline Waste & Probability-distribution functions & Risk assessment of sites contaminated with PCBs & [41] \\
\hline Nuclear waste & Probability theory & $\begin{array}{l}\text { Risk assessment of underground disposal of } \\
\text { nuclear waste. }\end{array}$ & {$[42]$} \\
\hline Municipal waste & Monte-Carlo simulation techniques & Risk assessment of a municipal waste incinerator & [14] \\
\hline Polluted site & Probability-distribution function & Risk of human exposure due to contaminated land & [43] \\
\hline Sludge & $\begin{array}{l}\text { Stochastic model incorporating uncertainty and } \\
\text { variability }\end{array}$ & $\begin{array}{l}\text { Identification of optimal sludge-management } \\
\text { strategies }\end{array}$ & {$[22]$} \\
\hline Groundwater & A rule-based fuzzy-set approach & $\begin{array}{l}\text { Risk analysis of nitrate-contaminated water to } \\
\text { assess risk to human health }\end{array}$ & [44] \\
\hline Groundwater & Decision support system based on fuzzy logic & Evaluation of the groundwater-pollution risk & [4] \\
\hline River-water quality & Fuzzy logic and arithmetic & $\begin{array}{l}\text { Risk assessment of water quality in the Ganges } \\
\text { River, India }\end{array}$ & [30] \\
\hline Polluted site & Fuzzy logic & $\begin{array}{l}\text { A model to assess the risk from a contaminated } \\
\text { site to the environment, in particular, human } \\
\text { health }\end{array}$ & {$[45]$} \\
\hline Polluted site & Fuzzy logic & $\begin{array}{l}\text { Evaluation of the risks that polluted sites might } \\
\text { pose to human health }\end{array}$ & [33] \\
\hline Soil & Fuzzy logic & $\begin{array}{l}\text { Realistic approach to decision making for risk- } \\
\text { based soil interpretations }\end{array}$ & [46] \\
\hline Agriculture & Fuzzy expert system & $\begin{array}{l}\text { Development of "Ipest" index to assess potential } \\
\text { risk of pesticides for the environment }\end{array}$ & {$[32]$} \\
\hline Hazardous waste facilities & Fuzzy reasoning & $\begin{array}{l}\text { Geographic expression of the concept "safe } \\
\text { distance" applied to hazardous-facility siting }\end{array}$ & [3] \\
\hline Ecotoxic substances releases & Fuzzy logic & $\begin{array}{l}\text { Methodology to assess risk of release of ecotoxic } \\
\text { substances in chemical plants }\end{array}$ & [47] \\
\hline Aquatic organisms & Fuzzy logic & $\begin{array}{l}\text { Risk assessment for aquatic organisms exposed to } \\
\text { brominated flame retardants (BFRs) }\end{array}$ & [48] \\
\hline Groundwater & Hybrid-fuzzy stochastic model & $\begin{array}{l}\text { Risk assessment of a petroleum-contaminated } \\
\text { groundwater system in Canada }\end{array}$ & [39] \\
\hline Groundwater & Integrated fuzzy-stochastic approach & $\begin{array}{l}\text { Risk assessment of groundwater contaminated by } \\
\text { xylene }\end{array}$ & [19] \\
\hline River-water quality & Monte-Carlo and fuzzy approaches combined & $\begin{array}{l}\text { Risk assessment for river-water-quality } \\
\text { management in Bhadra River (Southern India) }\end{array}$ & [49] \\
\hline Water quality & Probabilistic-fuzzy method & $\begin{array}{l}\text { Health-risk analysis due to exposure to } \\
\text { contaminated waters }\end{array}$ & {$[24,50]$} \\
\hline Soil & $\begin{array}{l}\text { Monte-Carlo approach combined with fuzzy } \\
\text { calculus }\end{array}$ & $\begin{array}{l}\text { Risk assessment for human exposure to cadmium } \\
\text { present in surface soils in the north of France }\end{array}$ & [16] \\
\hline
\end{tabular}

nitrate-contaminated groundwater. A nitrate-riskassessment methodology was developed to assist decision makers in estimating human-health risks corresponding to a particular nitrate dose to humans and in determining whether regulatory action needed to be taken to reduce the health risks. The uncertainty associated with assessing health risks of nitrate and its impact on results were represented using a fuzzy-set approach and incorporated into the nitrate-risk-assessment methodology.

Second, Uricchio et al. [4] proposed a decision-support system, based on fuzzy logic, for groundwater-pollutionrisk evaluation. This tool was conceived as a useful planning tool for decision makers involved in the management of sustainable use of natural resources.

In the water quality of rivers, McKone and Deshpande [30] considered how fuzzy logic and fuzzy arithmetic could be applied to risk assessment and environmental policy. They then presented a case study on risk assessment of water quality in the Ganges River in India.

The evaluation of the risk of polluted sites through fuzzy logic was studied by Lehn and Temme [45]. A model to assess the risk of a contaminated site for the environment, in particular human health, was developed. This estimation of the risk served as a basis for a decision-making tool (i.e. whether further steps with respect to that site needed to be taken). The information obtained from sites suspected of being contaminated was incomplete, uncertain or vague. For this reason, the use of fuzzy logic was appropriate in this model.

In 1999, Mohamed and Côté [33] also published a paper on risk assessment of contaminated sites. They developed a decision-analysis-based model to evaluate the risks that polluted sites might pose to human health. Quantitative estimates of risks were calculated for both 
carcinogenic and non-carcinogenic pollutants. Concepts of fuzzy-set theory were adopted to account for uncertainty in the input parameters (heterogeneity of soil and sediments), which were represented by fuzzy numbers.

For soils, Mays et al. [46] presented a methodology to demonstrate how fuzzy soil interpretations provided a realistic approach to decision-making for risk-based soil interpretations. According to him, fuzzy logic was a tool that could be used to characterize uncertainty in soil information so that a risk-based method of soil interpretations could be implied. Map units from a soil survey were used to demonstrate the appropriateness of soil for septic tank filter fields and tillage.

For agriculture, Van der Werf and Zimmer [32] proposed a fuzzy expert system to calculate an indicator, "Ipest", which reflects an expert perception of the potential risk of environmental impact of the application of a pesticide in a field crop. This impact was calculated through the analysis of the risk of three major compartments (i.e. groundwater, surface water and air).

In 1992, Lein [3] calculated the environmental risk from a hazardous waste facility using fuzzy logic. According to him, fuzzy logic was a very useful tool to assess the risk and performance of high-level radioactive waste repositories. The aim of the study was to produce a geographic expression of the concept "safe distance" using fuzzy reasoning when applied to the problem of siting a hazardous facility.

For releases of ecotoxic substances in chemical plants, Darbra et al. [47] presented a fuzzy-logic methodology to assess the risk of such releases. This method was based on the assessment of three macrovariables (i.e. the hazardousness of the substance, the vulnerability of the site and the level of preventive and protective measures). With this information, it was possible to obtain a final assessment of the risk of ecotoxic substances released from the chemical plants in the Piedmont Region of Italy.

The risk of brominated flame retardants (BFRs) on aquatic organisms was also studied by Darbra et al. [48]. These substances are considered dangerous pollutants because of their toxicity, stability and high liposolubility. They can therefore bioaccumulate and biomagnificate along the food chain, so they are often detected in aquatic organisms. The model presented in this paper was a preliminary risk-assessment tool able to support decision making for the management of releases of lipophilic substances in rivers.

\subsection{Hybrid applications}

There are also some hybrid applications to groundwaterrisk assessment. Chen et al. [39] developed a hybrid fuzzy-stochastic risk assessment (FUSRA) approach for examining uncertainties associated with both source and media conditions and evaluation criteria in a groundwater-quality-management system. It was applied to a petroleum-contaminated groundwater system in wes- tern Canada. Fuzzy and stochastic inputs were combined to assess the potential risk of exposure that could affect human health.

Recently, Li et al. [19] developed an integrated fuzzystochastic risk-assessment (IFSRA) approach to assess the risk associated with groundwater contamination by xylene. This model systematically quantified both probabilistic and fuzzy uncertainties associated with site conditions, environmental guidelines, and healthimpact criteria. The contaminant concentrations in groundwater predicted from a numerical model were associated with probabilistic uncertainties due to the randomness in modeling-input parameters, whereas the consequences of contaminant concentrations violating relevant environmental quality guidelines and health evaluation criteria were linked with fuzzy uncertainties.

For water quality, Vemula et al. [49] presented a methodology for evaluation of risk for a river-waterquality management. Monte-Carlo and fuzzy-logic approaches were used to treat the variables. Depending on the nature of each of the parameters involved in the risk assessment, one or both approaches were used to deal with uncertainty. The proposed methodology was demonstrated through a case study of Tunga-Bhadra River in southern India.

In 2004 and 2005, Kentel and Aral [24,50], proposed the use of fuzzy-set theory together with probability theory to incorporate uncertainties into the health-risk analysis due to exposure to contaminated waters. This approach was called probabilistic-fuzzy risk assessment (PFRA). Based on the form of available information, a combination of fuzzy-set and probability theories were used to incorporate parameter uncertainty and variability into mechanistic risk-assessment models.

Finally, for soil, Guyonnet et al. [16] proposed an approach combining Monte-Carlo random sampling of PDFs with fuzzy calculus. The approach was applied to a real case of estimating human exposure, via vegetable consumption, to cadmium present in the surface soils of an industrial site located in the north of France.

\section{Conclusions and future outlook}

When talking about environmental risk assessment, uncertainty cannot be left out as a parameter. It is inherent to any environmental system and it has two main origins - lack of environmental data, or randomness and variability of the system. Bearing this in mind, environmental parameters involved in risk assessment should be defined. However, they do not all have the same behavior and uncertainties associated with them.

There exist two main ways to deal with this uncertainty - probability theory or fuzzy logic. Applications of both approaches can be found in the literature, and even a combination of the two techniques is starting to attract 
further interest. This hybrid approach is based on the nature of the parameters, because some of the parameters are best suited to involve PDFs, while others, based on linguistic expressions, are better expressed with fuzzy numbers.

The most important output from risk assessment is the capacity to provide the basis of a decision-making process. The results of such decisions should be presented to the environmental managers and public in plain language and in line with the way humans think, rather than as difficult numbers or calculations.

The flexibility of fuzzy logic to express results in a natural language, in line with human reasoning, together with the possibility of dealing with uncertainties makes it highly recommended as a tool for use in communicating risk. However, the subjectivity involved due to human judgment can make one think that probabilistic methods, based on calculations, are more reliable. Such probabilistic methods are really effective when the information and the environmental data are available. However, in some cases, they can fail to model the environmental parameters, especially when these do not have really defined boundaries. In this situation, assigning PDFs to the parameters of the risk equation may not be the best option and using fuzzy logic may be better.

A combined approach may therefore be the best solution to deal with the uncertainties. Treating each parameter according its nature and information available could help to obtain a more realistic result for risk estimation.

In any case, there is no doubt that, for concepts, such as "safe", "tolerable" and "severe", boundaries are very hard to define. They are linguistic statements, and it is not easy to assign numerical values to them. But curiously, we make this kind of judgment every day in our lives without realizing it - "Driving fast is very dangerous" - "This behavior is intolerable" - "This is safe".

\section{Acknowledgements}

This Study was funded by the European Union through the projects RISKBASE (GOCE 036938), AQUATERRA (Project number 505428) and by the Spanish Ministry of Education and Science through the project CEMAGUA (CGL2007-64551/HID). This article reflects only the author's views and the EU is not liable for any use that maybe made of the information contained therein. Rosa Mari Darbra thanks the MINISTERIO DE EDUCACIÓN y CIENCIA for support through the Juan de la Cierva program.

\section{References}

[1] E. Scandurra, L'ambiente dell'uomo, Etas Libri, Milan, Italy, 1995.

[2] A. Finizio, S. Villa, Environ. Impact Assessment Rev. 22 (3) (2002) 235.
[3] J.K. Lein, Environ. Prof. 14 (1992) 257.

[4] V.F. Uricchio, R. Giordano, N. Lopez, J. Environ. Manage. 73 (3) (2004) 189.

[5] E. Kentel, M.M. Aral, Stochastic Environ. Res. Risk Assessment 21 (4) (2007) 405.

[6] D.J. Varnes, Commission on Landslides and Other Mass Movements, IAEG. Landslide Hazard Zonation: A Review of Principles and Practices, The UNESCO Press, Paris, France, 1984.

[7] A.N. Blair, B.M. Ayyub, W.J. Bender, Mar. Struct. 14 (1-2) (2001) 69.

[8] R.A. Linthurst, P. Bourdeau, R.G. Tardif, Methods to Assess the Effects on Chemical Ecosystems, SCOPE 53, Wiley, New York, USA, 1995 p. 416.

[9] L.W. Barnthouse, A framework for ecological risk assessment, in: R.A. Linthurst, P. Bourdeau, R.G. Tardif (Editors), Methods to Assess the Effects on Chemical Ecosystems, SCOPE 53, Wiley, New York, 1995, pp. 367-377.

[10] J. Casal, H. Montiel, E. Planas-Cuchi, S. Rodríguez, J.A. Vilchez, Anàlisi del Risc en Installacions Industrials, Edicions UPC, Barcelona, Spain, 1996, pp. 15-40.

[11] J.A. Vílchez, S. Carol, V. Espejo, X. Pérez, Aspectos probabilísticos a considerar en el análisis cuantitativo de riesgos de plantas de regasificación de gas natura, IV Jornadas de Fiabilidad. Confiabilidad. Fundamentos y nuevas tendencias, Instituto de Sistemas Inteligentes y Aplicaciones Numéricas en Ingeniería (IUSIANI), Las Palmas de Gran Canaria, Spain, 2002, pp.13-20.

[12] J.M. Wagner, U. Shamir, H.R. Nemati, Water Resour. Res. 28 (1992) 1233.

[13] C.D. Carrington, P.M. Bolger, Hum. Ecol. Risk Assessment 4 (1998) 253.

[14] M. Schumacher, M. Meneses, A. Xifro, J.L. Domingo, Chemosphere 43 (2001) 787.

[15] D. Borri, G. Concilio, E. Conte, Comput. Environ. Urban Syst. 22 (3) (1998) 299

[16] D. Guyonnet, B. Bourgine, D. Dobois, H. Fargier, B. Côme, J-P. Chilés, J. Environ. Eng. (Resten, VA) 129 (1) (2003) 68.

[17] G. Destouni, Water Resour. Res. 28 (1992) 793.

[18] S.Q. Chen, Comparing Probabilistic and Fuzzy Set Approaches for Design in the Presence of Uncertainty, Ph.D. Dissertation, Virginia Polytechnic Institute and State University, Blacksburg, Virginia, USA, 2000.

[19] J. Li, G.H. Huang, G. Zeng, I. Maqsood, Y. Huang, J. Environ. Manage. 82 (2) (2007) 173.

[20] R.M. Maxwell, S.D. Pelmulder, A.F.B. Tompson, W.E. Kastenberg, Water Resour. Res. 34 (1998) 833.

[21] R.M. Maxwell, W.E. Kastenberg, Stochastic Environ. Res. Risk Assessment 13 (1-2) (1999) 27.

[22] H.-W. Ma, Stochastic Environ. Res. Risk Assessment 14 (2000) 195.

[23] H.-W. Ma, Stochastic Environ. Res. Risk Assessment 16 (2002) 464.

[24] E. Kentel, M.M. Aral, Stochastic Environ. Res. Risk Assessment 18 (5) (2004) 324.

[25] A.L. James, C.M. Oldenburg, Water Resour. Res. 33 (1997) 2495.

[26] D. Guyonnet, B. Come, P. Perrochet, A. Parriaux, J. Environ. Eng. 125 (7) (1999) 660.

[27] L.A. Zadeh, Fuzzy Sets Syst. 11 (1983) 199.

[28] A.B. McBratney, I.O.A. Odeh, Geoderma 77 (1997) 85.

[29] L.A. Zadeh, Inf. Control 8 (1965) 338.

[30] T.E. McKone, A.W. Deshpande, Environ. Sci. Technol. 39 (2) (2005) 42A.

[31] G. Chen, T. Pham, Introduction to Fuzzy Sets, Fuzzy Logic and Fuzzy Control Systems, CRC Press, Boca Raton, FL, USA, 2001.

[32] H.M.G. Van Der Werf, C. Zimmer, Chemosphere 36 (1998) 2225.

[33] A.M.O. Mohamed, K. Cote, Waste Manage 19 (1999) 519. 
[34] S. Ferson, RAMAS Risk Calc 4.0 Software: Risk Assessment with Uncertain Numbers, Lewis Publishers, Boca Raton, FL, USA, 2003.

[35] A.C. Cullen, H.C. Frey, Probabilistic techniques in exposure assessment, Plenum Press, New York, USA, 1999.

[36] D. Vose, Quantitative Risk Analysis - A Guide to Monte Carlo Simulation Modeling, Wiley, Chichester, West Sussex, UK, 1996.

[37] A. Bardossy, I. Bogardi, L. Duchstein, Appl. Math. Comput. 45 (1991) 241.

[38] B. González, B. Adenso-Díaz, P.L. González-Torre, Resour. Conserv. Recycl. 37 (1) (2002) 61.

[39] Z. Chen, G.H. Huang, A. Chakma, J. Environ. Eng. 129 (1) (2003) 79.

[40] G.Passarella, M. Vurro, V.D. Agostino, G.D'Giuliano, M.J.Barcelona, Environ. Monit. Assessment 79 (1) (2002) 57.

[41] B. Batchelor, J. Valdés, V. Araganth, J. Environ. Eng. 124 (1998) 380.

[42] D. Draper, A. Pereira, P. Prado, A. Saltelli, R. Cheal, S. Eguilior, Comput. Phys. Commun. 117 (1) (1999) 142.
[43] P.A. Labieniec, D.A. Dzombak, R.L. Siegrist, J. Environ. Eng. 123 (3) (1997) 234.

[44] M.F. Dahab, Y.W. Lee, I. Bogardi, Water Sci. Technol. 30 (1994) 45.

[45] K. Lehn, K. Temme, Ecol. Modell. 85 (1) (1996) 51.

[46] M.D. Mays, C.S. Holzhey, I. Bogardi, A. Bardossy, Managing risk and variability with fuzzy soil interpretations, Site specific management for agricultural systems, Proc. Conf., Minneapolis, MN, USA, 1995, pp.187-198.

[47] R.M. Darbra, M. Demichela, S. Murè, Trans. Inst. Chem. Eng. Part B Process Safety Environ. Prot. 86 (2) (2008) 103.

[48] R.M. Darbra, E. Eljarrat, D. Barceló, Application of fuzzy logic to the preliminary risk assessment of fish pollution due to lipophilic substance releases in rivers, Riskbase, 1st Thematic Workshop, Lisbon, Portugal, 2007, pp. 119-122.

[49] V.R.S. Vemula, P.P. Mujumdar, S. Ghosh, J. Water Resour. Planning Manage 130 (5) (2004) 411.

[50] E. Kentel, M.M. Aral, Stochastic Environ. Res. Risk Assessment 19 (1) $(2005) 86$ 